\title{
Carbon Footprint and Built-up Land Footprint: Taipei Case Study
}

\author{
Yung-Jaan Lee ${ }^{1}$ \\ ${ }^{1}$ Research Fellow/Professor, Chung-Hua Institution for Economic Research, Taipei.
}

\begin{abstract}
The purpose of this study is to analyze whether the ecological footprint (EF) of Taipei residents differs between districts. In this study, EFs of residents of 12 districts in Taipei were calculated from the bottom-up approach using 445 questionnaires. The EF consists of six categories, and this study focuses only on the carbon footprint and the footprint of the built-up lands. The personal carbon footprint for Taipei residents is 0.0458 gha. The top five districts with the highest personal daily water footprint are Nangang, Wanhua, Neihu, Beitou and Xinyi. The top five districts with the highest daily carbon footprint are Xinyi, Wanhua, Beitou, Nangang and Shilin. The five districts with the highest daily EF are Xinyi, Wanhua, Beitou, Shilin and Nangang. The socioeconomic background of the respondents does not relate to the size of the water footprint and ecological footprint. Moreover, there is no statistical correlation between the individual's daily water footprint and daily EF. The socio-economic background of the respondents does not exhibit correlations with the size of the EFs.
\end{abstract}

\section{Introduction}

Environmental stresses caused by human activity have led to major changes in the planet, making climate change at the center of the global environmental concerns for decades. One of the main grounds of these environmental challenges is the greenhouse effect, which is believed to be mainly caused by $\mathrm{CO} 2$ emissions. The increase in greenhouse gases is for the most part due to economic growth and the fossil fuel burning.

Important changes induced by environmental stresses can lead to disasters. These disasters (e.g. debris flows) further create economic, social and environmental issues [1]. To appropriately measure sustainability, reliable data are required. Consequently, many indices are proposed to proceed strategies and assess the progress of sustainability. Although there is no single index can independently elucidate complicated concepts such as sustainability [2], it is feasible to quantify and monitor different dimensions of sustainability.

Many studies adopt carbon dioxide emissions as a byword for environmental deprivation. However, when considering environmental degradation, it is unreasonable to consider only a single index. Therefore, the Ecological Footprint (EF) is recommended [3]. Although there are certain restrictions [4], the ecological footprint account (EFA) is considered to be the first approximation of human pressure on the earth's ecosystem [5].

Taipei locates in the Taipei Basin, which is vulnerable to climate change impacts. Furthermore, with a population of nearly 2.7 million, Taipei has a very high population density. Consequently, whether there are relationships between vulnerabilities and the $\mathrm{EF}$ becomes a topic worthy of reflection in the urbanization of Taipei. This investigation elucidates whether there is any difference between the EFs of different districts in Taipei.

\section{Ecological Footprints}

The concept of ecological footprint was co-created in 1996 by William Rees and Mathis Wackernagel [3]. EF converts consumption of biological resources into a measurement of the amount of land and water needed to support these consumptions and waste disposal [6]. The Global Footprint Network (GFN) defines EF as measuring how much biological product lands an individual, population, or activity requires to produce all the resources they consume and absorb their waste. There are six components of EFs: cropland footprint, grazing footprint, forest footprint, fishing ground footprint, carbon footprint and the built-up land.

Ecological Footprint Account adds up the demand for eco-services for people using bioproductive land, allowing comparison with the available bioproductive land that provides these resources and services [4]. These bioproductive lands provide services such as resource regeneration and carbon sequestration, and human needs can be the consumption of a single activity, individuals, cities, nation or the whole population. The main contribution of this measurement tool is to provide a baseline to compare human needs for ecosystems and for ecosystems from a single product to the world [7].

* Corresponding author: yungjaanlee@gmail.com 
This, in turn, provides users with an understanding of local consumptions while gaining insight into how these consumptions are related to sustainable development issues [5].

In order to track environmental pressures, many countries have begun to explore the material flows of energy, water and other goods and services to meet the demand for water, energy, food, shelter and transport [89]. In contrast, the consumption-based footprint is being increasingly concerned by researchers, with greenhouse gas emissions from the residential and commercial sectors not allocated to producers.

Ecological footprint accounts usually use two main approaches: bottom-up or top-down [10]. The top-down approach uses national data to compute the country's footprint. This approach compares EFs of different cities in different countries, but it is only used in the assessment of single cities. The bottom-up approach, which does not calculate the national footprint, uses urban data to compute the city's EFs.

\section{Research Design}

\subsection{Research Method}

The individual EF estimated in this investigation consist of two items: carbon footprint and built-up land footprint. The individual carbon footprint questions in the questionnaire were based on the "Carbon Reduction Behavior Calculator" of Environmental Protection Administration. The footprint of built-up lands was calculated according to the building floor area of the housing unit of each person.

\subsection{Sampling Method}

This study uses a stratified random sampling method to select the respondents of 12 districts in Taipei. A total of 445 valid samples were obtained. Two investigators were recruited to assist the personal EF household survey, which lasted five months from December 2016 to April 2017.

\section{Results}

\subsection{One-way ANOVA of carbon footprint and built-up land footprint}

The carbon footprint and built-up land footprint were analyzed. Null hypothesis is that there are no differences among these footprints for the 12 districts. The results indicate that the daily carbon footprint in different districts reached a significant level $(\mathrm{p}<0.05)$ of 0.031 , indicating the rejection of the null hypothesis that the individual carbon footprint will vary from district to district (Table 1).

The homogeneity of variance (HOV) test is significant (.001); that is, there is no homogeneity between groups. Since there is no homogeneity between groups, only the Games-Howell test will be carried out.
Table 1: One-way ANOVA of carbon footprint and EF

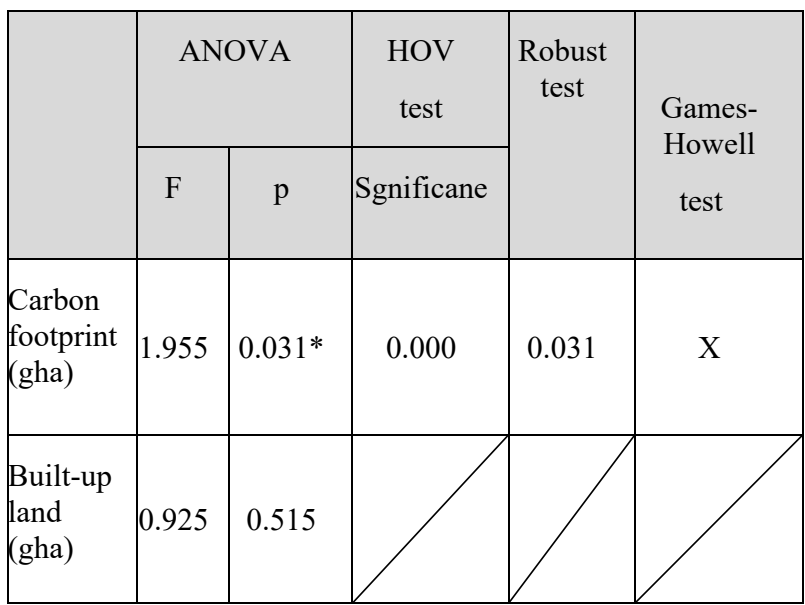

$\mathrm{p}<0.05$ significance

Based on the Game-Howell's post hoc tests, it was found that the individual carbon footprint was not significant (0.05) in each district. This indicated that there was no significant difference in this group.

\subsection{One-way ANOVA of socio-economic background and EF}

\subsubsection{Gender}

One-way ANOVA of footprints and gender shows that gender and personal daily carbon footprint and built-up land footprint did not reach significant levels, indicating that gender does not affect the footprints (Table 2).

Table 2: One-way ANOVA of gender and footprints

\begin{tabular}{|l|c|c|}
\hline \multirow{2}{*}{ Gender } & \multicolumn{2}{|c|}{ ANOVA } \\
\cline { 2 - 3 } & $\mathrm{F}$ & $\mathrm{p}$ \\
\hline Carbon footprint (gha) & 1.919 & 0.167 \\
\hline Built-up land footprint (gha) & 1.172 & 0.280 \\
\hline
\end{tabular}

\subsubsection{Age}

One-way ANOVA of age groups and footprints shows that age and individual daily carbon footprint did not reach a significant level, so no post hoc tests are needed. The personal built-up land footprint reached a significant level (0.029), showing the rejection of the null hypothesis. Age affects personal built-up land footprints. The HOV test of the built-up land footprint was different, so the Games-Howell test was carried out. The results showed that there was no significant difference between age groups (Table 3). 
Table 3: One-way ANOVA of age and EF

\begin{tabular}{|c|c|c|c|c|c|}
\hline \multirow{2}{*}{ Age } & \multicolumn{2}{|c|}{ ANOVA } & $\mathrm{HOV}$ & \multirow{2}{*}{$\begin{array}{l}\text { Robust } \\
\text { test }\end{array}$} & \multirow{2}{*}{$\begin{array}{c}\text { Games- } \\
\text { Howell } \\
\text { test }\end{array}$} \\
\hline & $\mathrm{F}$ & $\begin{array}{l}\text { Signific } \\
\text { ance }\end{array}$ & $\begin{array}{l}\text { Signific } \\
\text { ance }\end{array}$ & & \\
\hline $\begin{array}{l}\text { Carbon } \\
\text { footprint } \\
\text { (gha) }\end{array}$ & 1.103 & 0.355 & & & \\
\hline $\begin{array}{l}\text { Built-up } \\
\text { land } \\
\text { (gha) }\end{array}$ & 2.725 & $0.029^{*}$ & 0.000 & 0.012 & $X$ \\
\hline
\end{tabular}

$* \mathrm{p}<0.05$, significant

\subsubsection{Personal income}

One-way ANOVA of individual income and footprints shows that personal income, personal carbon footprint, personal built-up land footprint are not significantly different and no post hoc tests are needed (Table 4).

Table 4: One-way ANOVA of income and footprints

\begin{tabular}{|l|c|c|}
\hline \multirow{2}{*}{ Personal Income } & \multicolumn{2}{|c|}{ ANOVA } \\
\cline { 2 - 3 } & $\mathrm{F}$ & $\mathrm{p}$ \\
\hline Carbon footprint (gha) & 1.261 & 0.274 \\
\hline Built-up land footprint (gha) & 0.907 & 0.490 \\
\hline
\end{tabular}

\section{Conclusions and Suggestions}

\subsection{Conclusions}

The EFA adopted in this investigation is different from most EFAs. This investigation calculated only the carbon footprint and built-up land footprint of the six categories of EF.

As Lee and Peng [11] refer to the IEA's top-down guidelines, their carbon footprints included carbon dioxide emitted by the national development of electricity and carbon dioxide emitted by national constructions; whereas, this study only estimates individual carbon footprint for personal consumption. The calculated personal carbon footprint for Taipei is 0.0458 gha.

One-way ANOVA was carried out to examine the relationships between individual footprints and districts. The results found that the daily carbon footprint in different districts of Taipei reached a significant level, indicating that the individual's daily carbon footprint vary from district to district. The personal built-up land footprint did not reach significant levels. Using Game-
Howell's post hoc tests, it was found that the individual's daily carbon footprint was not significant in each district.

Gender, age and personal income had no impacts on carbon footprint and built-up land footprint of Taipei residents.

\subsection{Suggestions}

As the survey is generally executed during the daytime, it is easier for the head of households, retirees and seniors to be investigated, while the working-class groups are less likely to be investigated. In addition, apart from the low number of young respondents due to the timing of the questionnaire, the rest are broadly in line with the current situation in Taipei.

The findings of this study point out that although the residents of different districts of Taipei show different footprint sizes, no statistical correlation is found between districts or social background of the respondents. Follow-up studies can analyze in greater depth the footprints of various daily consumptions such as food and clothing.

Future studies can elucidate cropland footprints, grazing footprints, forest footprints and fishing ground footprints from the bottom up questionnaire survey.

\section{References}

1. G. Mezosi, T. Bata, B.C. Meyer, et al., Climate change impacts on environmental hazards on the Great Hungarian Plain, Carpathian Basin. Int. J. Disaster Risk Sci. 5, 136-146 (2014)

2. A. Galli, T.O. Wiedmann, E. Ercin, D. Knoblauch, B.R. Ewing, S. Giljum, Integrating ecological, carbon and water footprint into a "Footprint Family" of indicators: definition and role in tracking human pressure on the planet. Ecol. Indic. 16, 100-112 (2012)

3. M. Wackernagel, W. Rees, Our ecological footprint: Reducing human impact on the Earth (New Society Publishers: Gabriola Island, 1996).

4. A. Galli, M. Giampietro, S. Goldfinger, E. Lazarus, D. Lin, A. Saltelli, M. Wackernagel, F. Müller Questioning the ecological footprint. Ecol. Indic. 69 (October), 224-232 (2016)

5. W. Baabou, N. Grunewald, C. Ouellet-Plamondon, M. Gressot, A. Galli, The ecological footprint of Mediterranean cities: awareness creation and policy implications. Environ. Sci. Policy 69, 94-104 (2017)

6. J. Bowyer, K. Fernholz, J. Howe, S. Bratkovich, Comparing the ecological footprint of the U.S. and the E.U. (Dovetail Partners, Minneapolis, 2009)

7. J. Kitzes, A. Galli, M. Bagliani, J. Barrett, G. Dige, S. Ede, K. Erb, S. Giljum, H. Haberl, C. Hails, et al., A research agenda for improving national ecological footprint accounts. Ecol. Econ., 68, 1991-2007 (2009)

8. A. Chavez, A. Ramaswami, Articulating a transboundary infrastructure supply chain greenhouse gas emission footprint for cities: mathematical 
relationships and policy relevance. Energy Policy 54, 376-384 (2013)

9. A. Ramaswami, A. Chavez, M. Chertow, Carbon footprinting of cities and implications for analysis of urban material and energy flows. Sustain. Urban Syst. 16(6), 783-785 (2012)

10. J. Moore, M. Kissinger, W.E. Rees, An urban metabolism and ecological footprint assessment of metro Vancouver. J. Environ. Manage. 124, 51-61 (2013)

11. Y.J. Lee, L.-P. Peng, Taiwan's ecological footprint (1994-2011). Sustainability. 6(9): 6170-6187 (2014) 